Thaís dos Reis Vilela'

Ohttps://orcid.org/0000-0002-4768-5559

Marina Monzani da Rocha² O. https://orcid.org/0000-0003-4995-7906

Neliana Buzi Figlie’

Ohttps://orcid.org/0000-0001-8846-7315

Sandra Cristina Pillon ${ }^{3}$

Ohttps://orid.org/0000-0001-8902-7549

Alessandra Diehl'

(D) htps://orcid org/0000-0002-9252-3284

Jair de Jesus Mari

Ohttps:// orcid.org/0000-0002-5403-0112

\section{Domestic violence and risk of internalizing and externalizing problems in adolescents living with relatives displaying substance use disorders}

\author{
Violência doméstica e risco de problemas de internalização e externalização em \\ adolescentes com familiares apresentando transtornos por uso de substâncias
}

D0I: $10.1590 / 0047-2085000000268$

\begin{abstract}
Objective: To investigate the association between exposure to domestic violence and increased risk of internalizing and externalizing problems and substance use among adolescents living with relatives with substance use disorder (SUD) at a low-income community of São Paulo, Brazil. Methods: A crosssectional study was conducted with 102 adolescents aged 12-17 years $(M=14.2, S D=1.7)$ who were living with relatives suffering from SUD. Outcomes were measured using the Youth Self-Report (YSR), psychosocial stress factors questionnaire, Drug Use Screening Inventory (DUSI) and Phrase Inventory of Intrafamily Child Abuse (PIICA). Results: The sample presented high prevalence of emotional/behavioral problems with YSR's scores in the clinical range for Internalizing Problems (24.5\%), Externalizing Problems (21.6\%), and Total Problems (26.5\%). The presence of mental health problems predicted substance use $(\mathrm{PR}=2.22 ; 95 \% \mathrm{Cl}=1.2-4.13)$, and substance use predicted increased risk of mental health problems. Alcohol use predicted more than double the risk of emotional/behavioral problems (PR $=2.01 ; 95 \% \mathrm{Cl}$ $=1.08-3.76$ ), while illicit drug use was associated with an almost threefold increase in the prevalence of Internalizing ( $\mathrm{PR}=2.87 ; 95 \% \mathrm{Cl}=1.19-6.89)$ and Externalizing Problems ( $\mathrm{PR}=3.3 ; 95 \% \mathrm{Cl}=1.35-8.04)$.

Conclusion: Adolescents of relatives with SUD are at risk of developing emotional and behavioral problems. These findings reinforce the need to develop public mental health policies, which include protective interventions to adolescents living in families affected by substance use disorders.
\end{abstract}

KEYWORDS

Substance-related disorders, adolescent behavior, violence exposure, domestic violence, low-income population.

\section{RESUMO}

Objetivo: Investigar a associação entre exposição à violência doméstica e aumento do risco de problemas internalizantes e externalizantes e uso de substâncias entre adolescentes que vivem em famílias com transtorno por uso de substâncias (TUS) em uma comunidade de baixa renda de São Paulo, Brasil. Métodos: Estudo transversal com 102 adolescentes de 12 a 17 anos $(M=14,2$, $D P=1,7)$ que vivem com familiares com TUS. Os desfechos foram avaliados por meio do Inventário de Autoavaliação para Adolescentes (YSR), questionários de fatores de estresse psicossociais, Drug Use Screening Inventory (DUSI) e Inventário de Frases de Violência Doméstica (IFVD). Resultados: A amostra apresentou altas taxas de problemas emocionais/comportamentais no YSR, sendo 24,5\% com escores na faixa clínica para Problemas Internalizantes, 21,6\% para Problemas Externalizantes e 26,5\% para Problemas Totais. A presença de problemas de saúde mental foi preditora do uso de substâncias (RP $=2,22$; IC 95\% =1,2-4,13) e o uso de substâncias foi preditor do aumento da prevalência de problemas emocionais/comportamentais. O uso de álcool prediz mais do que o dobro do risco de problemas emocionais/comportamentais ( $\mathrm{RP}=2,01$; IC 95\% = 1,08-3,76), enquanto o uso de substâncias ilícitas esteve associado com um aumento de quase três vezes na prevalência de Problemas Internalizantes ( $R P=2,87$; IC 95\% =1,19-6,89) e Externalizantes $(\mathrm{RP}=3,3 ; \mathrm{IC} 95 \%=1,35-8,04)$. Conclusão: Adolescentes que convivem diretamente com familiares com TUS estão em risco para o desenvolvimento de problemas emocionais/comportamentais. Os achados reforçam a necessidade de políticas públicas que incluam programas de proteção para adolescentes que vivem em famílias com transtornos causados pelo uso de substâncias.

PALAVRAS-CHAVE

Transtornos relacionados ao uso de substâncias, comportamento do adolescente, exposição à violência, violência doméstica, população de baixa renda.

Received in: Mar/07/2020. Approved in: Apr/05/2020

1 Federal University of São Paulo (Unifesp), Department of Psychiatry, São Paulo, SP, Brazil.

2 Mackenzie Presbyterian University, Developmental Disorders Post-Graduate Program, São Paulo, SP, Brazil.

3 University of São Paulo (USP), Department of Psychiatric Nursing and Human Science, São Paulo, SP, Brazil.

Address for correspondence: Thaís dos Reis Vilela. Departamento de Psiquiatria, Escola Paulista de Medicina da Universidade Federal de São Paulo. Rua Major Maragliano, 241, Vila Mariana - 04017-030 - São Paulo, SP, Brasil. E-mail: thaisvilela1@gmail.com 


\section{INTRODUCTION}

Domestic violence and substance-related disorder remains a significant public health concern contributing to major social, economic, developmental and psychological stressors that affect families and societies within multiple generations, producing a huge global disease burden ${ }^{1,2}$. Although substance use disorder (SUD) is presented as a problem of the dependent, families are also profoundly affected by the family member's addiction ${ }^{3}$. These are under-researched areas, especially in low- and middle-income countries (LMICs), with important implications for policies and clinical interventions, particularly for the mental health development of children and adolescents in vulnerable situations ${ }^{24,5}$.

The prevalence of children and youths living with a person suffering from SUD is high. In the United States (US), about 8.7 million (12.3\%) children and youths (under 18 years old) live in households with at least one parent with SUD ${ }^{6}, 7.5$ million (10.5\%) live in households with at least one parent who has an alcohol use disorder (AUD), and 2.1 million (2.9\%) live in households with at least one parent who had a previous illicit drug use disorder ${ }^{6}$. A Swedish study demonstrated that approximately $3 \%-4 \%$ of all children under the age of 18 years have experienced parent's AUD'. British national surveys indicated that $6 \%$ of children under the age of 16 years live with an adult who has an $\mathrm{AUD}^{8}$. Brazilian data from the National Survey of Families of Substance Dependents held in 2012, including 3,153 families, indicated the presence of social vulnerabilities and SUD in the homes. The same research estimated that households in Brazil have an average of 3.5 people, which leads to an estimative of a least 28 million people living with a SUD dependent?

Evidence shows that adolescents whose parents suffer from SUD are at great risk of developing mental health disorders or behavior problems themselves (e.g., poorer parent-child relationships and more emotional symptoms, low self-esteem, loneliness and depression), since substance use in parents increases the possibility of substance abuse by their children ${ }^{10,11}$. This increase in risk of addiction results from both genetic and environmental factors. When the parent has substance abuse problems, the family is generally unsafe, unpredictable, chaotic, and disorganized. Parents with SUD not only have fewer parenting skills, but also have less control and supervision over their children ${ }^{10}$. Moreover, parent-child interaction quality is not satisfactory, and more parent-child conflicts might be observed in such families. These issues can have negative effects on the socialization process (social skills training), and can lead to the development of depressive symptoms, besides internalizing and externalizing problems $s^{10,12,13}$.

Additionally, children living in slums are at high risk of multiple exposures to violence. Fidalgo et al. found that having experienced any violent childhood event and living under a low socioeconomic status (SES) were significantly associated with both having internalizing and externalizing disorders according to the DSM-IV diagnostic criteria ${ }^{14}$.

This study aimed at: (1) estimating the prevalence of emotional and behavioral problems among adolescents aged 12-17 years living with relatives that suffer from a SUD in a low-income community of São Paulo, southeastern Brazil; (2) investigating the association between exposure to domestic violence and the increasing risk of internalizing and externalizing problems; and (3) evaluating substance use among these adolescents.

\section{METHODS}

\section{Study design and setting}

A cross-sectional study was conducted in Jardim Ângela, a conglomerate of slums located in one of the most vulnerable regions of São Paulo city. The Jardim Ângela district belongs to the sub-municipality of M'Boi Mirim, which is $62.1 \mathrm{~km}^{2}$ in area; of the 563,305 inhabitants, 295,434 reside in Jardim Ângela, situated on the extreme outskirts of the city of São Paulo with alarming rates of social exclusion, economic helplessness and urban violence. The situation of Jardim Ângela is even more alarming when the effects of exposure to such high social vulnerability on future generations are taken into account. The population is predominantly of young people: $52.9 \%$ are under 24 years old. The Youth Vulnerability Index is 76 on a scale of $0-100$, for which 65 is the cut-point for the most vulnerable districts ${ }^{15}$. The precarious economic conditions, and the lack of opportunities to enter the formal labor market, result in an extremely favorable environment for the growth of drug trafficking, which is also an informal job market, especially for young people $e^{16}$. A study conducted by Akerman and Bousquat ${ }^{17}$ showed that Jardim Ângela was the most violent neighborhood in the world, with a homicide rate of 111.52 cases per 100,000 inhabitants - much higher than the rate for São Paulo city (42.59 cases per 100,000 inhabitants).

\section{INSTRUMENTS}

Sociodemographic questionnaire: with questions to assess sex at birth (female, male), age group $(\leq 14, \geq 15)$, marital status (married, unmarried), race (white, non-white), years of education $(\leq 8, \geq 9)$, religious affiliation (yes, no), current occupational status (employed, not employed).

\section{Brazilian Association of Research Companies scale:} this determines the purchasing power of urban families and takes into consideration the possession of household goods, and householder's educational level. Families are sorted into subgroups ( $A 1, A 2, B 1, B 2, C, D$, and E) according to their 
score. Class A1 represents the most-favored economic level, while Class $E$ represents the least-favored one ${ }^{18}$.

Family CAGE-AID (Adapted to Include Drugs): a screening tool with four items that aims to detect family problems related to substance use. The Family CAGE was adapted by Frank et al. ${ }^{19}$ from the original CAGE questionnaire and presented strong internal consistency (Cronbach's alpha coefficients of 0.84 to 0.89$)^{19}$. For this study, it was adapted to measure substance problems as well, following Brown and Rounds' suggestion ${ }^{20}$. Family CAGE-AID is advantageous for its potential in detecting substance dependence in community or epidemiological studies, when the primary user may be unavailable or non-cooperative ${ }^{21}$. In our study, the cut-off point used was of at least one affirmative answer, which was established by Castells and Furlanetto22, with good sensitivity (93.8\%) and specificity (85.5\%).

Psychosocial stress factor questionnaire: which investigates situations of psychosocial stress. The selection of items was based on the criteria established by the International Classification of Diseases (ICD-10): psychiatric hospitalization of a family member, severe disease in the family, suicide of a family member, attempted suicide of a family member, problems with the law, death in the family, and physical aggression among family members ${ }^{23}$.

Drug Use Screening Inventory (DUSI): adapted and validated by De Micheli and Formigoni ${ }^{24}$ for Brazilian' samples, with $80 \%$ sensitivity, and $90 \%$ specificity ${ }^{25}$. In this study, only data on substance type and frequency of use were analyzed. The Brazilian version of the DUSI presented strong internal consistency reliability for the whole sample (drug-dependents and non-drug-dependent adolescents), with an average across all 10 scales of $0.96(S D=0.02)$ for Cronbach's alpha reliability coefficient, and $0.88(S D=0.08)$ for the split-half reliability coefficient.

Youth Self-Report (YSR): allows adolescents (aged 11-18 years) to assess their own emotional and behavioral problems ${ }^{26}$. Includes three broad-band scales: (1) Internalizing Problems, with problems such as anxiety, depression, somatic complaints, and social withdrawal; (2) Externalizing Problems, which includes rule-breaking behavior, and aggressive behavior; and (3) Total Problems, the sum of all problem's items. Scores are classified within normal and clinical range in comparison with a normative sample of adolescents non-referred for mental health services. The version used in this study was validated for Brazilian adolescents ${ }^{27}$, with good fit to the original factorial model (root-mean-square error of approximation $=0.032$ ), high internal consistency values (Cronbach's alpha for Total Problems' scale $=0.924)$, and acceptable sensitivity (35.4\%) and specificity (83.5\%) rates ${ }^{27}$.

Phrase Inventory of Intrafamily Child Abuse (PIICA): developed by Agosta et al.28,29 to investigate exposure to domestic violence and/or abuse. PIICA aims to assess evidence or suspicion of domestic violence and associated disorders that may occur due to the experience of physical and/or sexual violence. It was validated in Brazil by Tardivo and Pinto Junior ${ }^{30}$, with indicatives of good internal consistency (Cronbach's alpha $=0.85$ ).

\section{Procedures}

The adolescents were recruited from two social programs that are offered for low-income families in the Jardim Ângela neighborhood: The Utility Intervention and Support Center for Children of Substance Abusers (CUIDA) and Centers for Children and Adolescents (CCAs).

CUIDA is a preventive program aimed at assisting children and adolescents who live with addicted family members. It offers mental health assistance, including psychological, social, and medical care. Moreover, other activities, such as educational, recreational, musical, sports, and computer training, are offered ${ }^{31}$. CUIDA's database includes 791 children and adolescents who attended the program. During data collection, 273 were still adolescents (12 to 17 years old). Researchers tried to locate all participants by either a phone call or home visits. A total of 67 (25\%) adolescents agreed to participate in the study, 142 (52\%) were not located, 30 (11\%) refused to participate, 23 (8\%) were institutionalized and were not living with their family of origin, 2 (0.7\%) reported that they had never attended CUIDA, and 9 (3.3\%) had problems with drugs, drug trafficking, and were homeless or imprisoned.

CCAs are attended by children and adolescents with disabilities; who were withdrawn from child labor, and/or subjected to other rights violations; who returned to the family after a protective measure; whose families are beneficiaries of income transfer programs; and who live in vulnerable and risky situations. The program acts in the scope of the prevention of social risk situations by offering recreational, socio-educational, sports, cultural, and recreational activities that foster the development of children and adolescents and their creativity, cognitive, and group living skills. Thirty-five (35) children were recruited from this program.

In both programs (CUIDA and CCAs), all activities take place outside the regular school-period, so that all youths can attend school regularly. The inclusion criteria for the present study was to live with at least one family member with SUD and to reside in Jardim Ângela. The exclusion criteria were not having relatives with SUD, being under an arrest warrant, and not agreeing to participate in the study.

The exposure to relatives with SUD was informed by professionals from the two programs where the sample was recruited. This information was confirmed through the Family CAGE-AID questionnaire to identify only those who were living with a family member with SUD. The researcher, a trained psychologist, conducted a 60-minute face-to-face individual interview with all the participants, after authorization of the caregiver, either in the mentioned programs or during home visits. 


\section{Statistical analysis}

The variables were described by absolute frequency and percentage. To estimate the prevalence ratios (PR), a log-binomial regression model was used (variables were binary $)^{32}$. All analyses were performed using SAS 9.2 software, with a $5 \%$ significance level.

Socioeconomic variables, psychosocial stressors, and the means of the violence scores versus the response variable (substance use; Internalizing, Externalizing, and Total Problems) were entered into the simple regression model. Simple regression was performed, and the sample size was a limiter to follow the adjusted regression. Although the calculation of gross prevalence ratios does not point to the prevalence ratio of each variable in the presence of others, this model offers the measure of correct effect and its association with the outcomes analyzed (substance use and Internalizing, Externalizing and Total Problems).

\section{Ethical issues}

The study was approved by the Ethical Committee of the University (CEP 1843/09) and by the Ethical Research Committee of the Municipal Health Department of São Paulo (CAAE: 05.174/11), taking into account all ethical guidelines displayed on Resolution No. 196/96 of the National Health Council of the Ministry of Health. All protocols included an informed consent form, properly signed, ensuring the anonymity of the participant and confidentiality of information. All guardians were informed of the nature, content, and purpose of the interviews and signed an Informed Consent Form authorizing the participation.

\section{RESULTS}

A total of 102 adolescents who were living with relatives suffering from SUD participated in the study. The sample included 58 girls (56.9\%), and 44 boys (43.1\%), aged 12-17 years ( $M=14.2, S D=1.7)$. The majority of participants had mixed race background (48\%), 32.4\% were white, and $19.6 \%$ black. Class C was the most prevalent economic status (66.7\%), followed by class D (20.6\%) and B2 (12.7\%). Having some religious background was reported by $71.6 \%$. Descriptive statistics with sociodemographic data and exposure to situations of psychosocial stress reported by the adolescents are presented on table 1.

Regarding the parents, 51\% were married or living together, 38.2\% were divorced or separated, 5.9\% were single, and $4.9 \%$ were widowed. On living situation, 49\% lived with both father and mother, $27.5 \%$ only with mother, 6.9\% with mother and stepfather, and $7.8 \%$ with other relatives. The majority (94.1\%) was currently studying, and $7.8 \%$ had a job.
Table 1. Sociodemographic factors, stressful events, substance use, and mental health problems $(N=102)$

\begin{tabular}{|c|c|}
\hline Variables & $n(\%)$ \\
\hline \multicolumn{2}{|l|}{ Adolescent characteristics } \\
\hline Gender (female) & $58(56.9)$ \\
\hline Ethnic group (non-white) & $69(67.6)$ \\
\hline \multicolumn{2}{|l|}{ Brazil Economic Classification Criteria } \\
\hline Class B2 & $13(12.7)$ \\
\hline Class C & $68(66.7)$ \\
\hline Class D & $21(20.6)$ \\
\hline Religious background & $73(71.6)$ \\
\hline \multicolumn{2}{|l|}{ Parents' marital status } \\
\hline Married or living together & $52(51.0)$ \\
\hline \multicolumn{2}{|l|}{ Psychosocial stress factors } \\
\hline \multicolumn{2}{|c|}{ Family stressful situations in the last 12 months } \\
\hline Psychiatric hospitalization & $8(7.8)$ \\
\hline Family severe disease & $23(22.5)$ \\
\hline Suicide & $2(2.0)$ \\
\hline Suicide attempt & $4(3.9)$ \\
\hline Problems with the law & $8(7.8)$ \\
\hline Death of a family member & $18(17.6)$ \\
\hline Physical aggression between family & $28(27.5)$ \\
\hline \multicolumn{2}{|l|}{ Substance user characteristics } \\
\hline \multicolumn{2}{|l|}{ Number of substance abusers who coexist } \\
\hline One substance abuser & $69(67.6)$ \\
\hline More than one substance abuser & $30(29.4)$ \\
\hline \multicolumn{2}{|l|}{ Substance abuser member } \\
\hline Mother & $7(6.9)$ \\
\hline Father & $47(46.1)$ \\
\hline Mother and father & $10(9.8)$ \\
\hline Brothers or sisters & $4(3.9)$ \\
\hline Second-degree relatives & $34(33.3)$ \\
\hline \multicolumn{2}{|c|}{ Substance consumed by addicted family } \\
\hline Alcohol & $57(57.0)$ \\
\hline Illicit drugs & $43(43.0)$ \\
\hline \multicolumn{2}{|l|}{ Substance use by the adolescent } \\
\hline Alcohol & $26(25.5)$ \\
\hline Tobacco & $5(4.9)$ \\
\hline Illicit drugs & $3(2.9)$ \\
\hline \multicolumn{2}{|l|}{ Emotional and behavioral problems } \\
\hline Internalizing Problems & $25(24.5)$ \\
\hline Externalizing Problems & $22(21.6)$ \\
\hline Total Problems & $27(26.5)$ \\
\hline
\end{tabular}

On sexual behavior, 29.4\% reported having some sort of sexual activity. Of those, $14.3 \%$ did not use any birth control, $14.3 \%$ used it sometimes, $14.3 \%$ used it usually, and $57.1 \%$ always used it. The contraceptive method used by most adolescents was condom (76.9\%), and 19.2\% used 
combined methods. Regarding the association of substance use and sex, 26\% never consumed alcohol or drugs to have sexual intercourse, but $2 \%$ declared that they did. Three adolescents (2.9\%) reported having children. No teenager reported having problems with the law.

\section{Family psychosocial stress factors}

Table 1 displays the exposition to psychosocial stress factors. It is notetaking that $66.7 \%$ were exposed to some important stressor event in the last 12 months, with a high prevalence of exposure to family psychosocial stressors, such as physical aggression (27.5\%), severe disease (22.5\%), death (17.6\%), problems with the law (7.8\%), hospitalization for psychiatric disorder (7.8\%), suicide attempt (3.9\%), and suicide (2\%).

\section{Relatives' SUD characteristics and prevalence of substance use by the adolescents}

Most adolescents (67.6\%) cohabited with one relative with SUD, but $29.4 \%$ lived with more than one. For $46.1 \%$, the relative with SUD was the fathers, $6.9 \%$ was for the mother, and $9.8 \%$ was for both parents. Moreover, 3.9\% lived with brothers or sisters who suffered from SUD, and $33.3 \%$ with other relatives, such as grandparents and uncles. Most of the family members with SUD (57\%) used alcohol, whereas $43 \%$ consumed illicit drugs (see table 1). The illicit substances users were mostly poly-users (79\%), while $12 \%$ used only marijuana, $7 \%$ cocaine, and 2\% solvent.

Regarding substance use by adolescents, $25.5 \%$ declared that they consume alcoholic beverages, $4.9 \%$ were tobacco smokers, and $2.9 \%$ were illicit drug users. The frequency of use was: monthly (19\%), weekly (1\%), and almost every day (1\%). Consumption in the last month was reported by $79 \%$ of the sample. For tobacco, $96.1 \%$ reported no consumption in the last month. However, $2 \%$ reported consumption in the last month, $1 \%$ weekly consumption, and $1 \%$ almost every day. Only one adolescent declared monthly use of cocaine, and $2 \%$ reported monthly use of marijuana. The younger adolescents (aged 12-14 years) presented lower substance use prevalence $[\mathrm{PR}=0.1$; $95 \%$ confidence interval $(\mathrm{Cl})=0.03$ 0.32] in comparison with the older ones (aged 15-17 years).

\section{Prevalence of emotional and behavioral problems and associated risk factors}

The prevalence of scores in the clinical range of the YSR was 24.5\% for Internalizing Problems, 21.6\% for Externalizing Problems, and 26.5\% for Total Problems, as shown in Table 1. Gender, age group, ethnic group, economic status, religious background, and parental marital status had no association with an increased prevalence of Internalizing, Externalizing, and Total Problems. Moreover, mothers and fathers schooling did not predict increases in problems' scores (see table 2).

The number of relatives with SUD and their relationship with the adolescents did not predict an increase in the prevalence of Internalizing, Externalizing, and Total Problems. The type of substance consumed by the relative with SUD did not affect the prevalence of Internalizing and Externalizing problems, but it affected the prevalence of Total Problems: the use of illicit substances increased its prevalence (PR = $1.93 ; 95 \% \mathrm{Cl}=1-3.72)$.

The consumption of any substance by the adolescent, either legal or illegal, predicted more than double the risk of emotional and behavioral problems. Specifically, alcohol use was related with a twofold risk for Total Problems ( $P R=2.01$; $95 \% \mathrm{Cl}=1.08-3.76$ ), while tobacco use was related to more than a threefold increase in the prevalence of Externalizing Problems $(\mathrm{PR}=3.06 ; 95 \% \mathrm{Cl}=1.35-6.97)$, and double the risk for Total Problems (PR $=2.43 ; 95 \% \mathrm{Cl}=1.09-5.37)$. Illicit drug use was associated with an almost threefold increase in the prevalence of Internalizing Problems (PR $=2.87 ; 95 \%$ $\mathrm{Cl}=1.19-6.89)$, more than three times the prevalence of Externalizing Problems ( $P R=3.3 ; 95 \% \mathrm{Cl}=1.35-8.04)$, and double risk of Total Problems ( $\mathrm{PR}=2.64 ; 95 \% \mathrm{Cl}=1.11-6.29)$, as shown in table 2 .

The presence of emotional and behavioral problems also predicted substance use. When Externalizing and Total Problems were in the clinical range, the prevalence of substance use was increased twofold for Externalizing Problems ( $\mathrm{PR}=2.14 ; 95 \% \mathrm{Cl}=1.15-3.99)$ and Total Problems $(\mathrm{PR}=2.22 ; 95 \% \mathrm{Cl}=1.2-4.13)$

Exposure to family psychosocial stressors was associated with an increase of two to three times in the prevalence of Internalizing Problems. No association was found with stressors and the increase in prevalence of Externalizing and Total Problems. The following risk factors predicted increases in Internalizing Problems: suicide attempt in the family (PR = $3.34 ; 95 \% \mathrm{Cl}=1.70-6.56)$, and family problems with the law $(P R=2.24 ; 95 \% \mathrm{Cl}=1.02-4.93)$ (see table 2).

\section{Exposure to domestic violence}

Adolescent exposure to domestic violence increases the risk of developing mental health problems. The outcomes of domestic violence, including cognitive, emotional, behavioral, and physical disorder, had a positive association with the increase of Internalizing, Externalizing and Total problems. When adolescents were divided into two groups using their YSR's scores (normal $x$ clinical range), PIICA's scores were higher for the clinical group.

Several domestic violence outcomes were associated with the increased risk of Internalizing Problems: cognitive disorders ( $\mathrm{PR}=1.39 ; 95 \% \mathrm{Cl}=1.14-1.71)$, emotional disorders $(\mathrm{PR}=1.16 ; 95 \% \mathrm{Cl}=1.10-1.23)$, behavioral disorders (PR = $1.16 ; 95 \% \mathrm{Cl}=1.04-1.30)$, and physical disorders $(\mathrm{PR}=1.90$; $95 \% \mathrm{Cl}=1.25-2.88)$. Moreover, were cognitive disorders (PR $=1.28 ; 95 \% \mathrm{Cl}=1.04-1.59)$, emotional disorders $(\mathrm{PR}=1.15$; $95 \% \mathrm{Cl}=1.05-1.25)$, and physical disorders (PR $=1.64 ; 95 \% \mathrm{Cl}$ $=1.02-2.62)$. Lastly, cognitive $(P R=1.5 ; 95 \% C l=1.24-1.81)$, 
emotional $(P R=1.11 ; 95 \% C l=1.02-1.21)$, and physical disorders ( $P R=2 ; 95 \% \mathrm{Cl}=1.41-2.83$ ) were also associated with the increased risk of Total Problems. Overall, results indicated that the higher the PIICA score, the greater the prevalence of YSR's emotional and behavioral problems. Social disorder was the only scale for which no significant differences were found between YSR's clinical and nonclinical groups, as shown in table 3 .

Table 2. Prevalence ratios of emotional and behavioral problems in relation to associated risk factors $(N=102)$

\begin{tabular}{|c|c|c|c|c|c|c|c|c|c|c|c|c|}
\hline \multirow[b]{2}{*}{ Variables } & \multicolumn{4}{|c|}{ Internalizing Problems } & \multicolumn{4}{|c|}{ Externalizing Problems } & \multicolumn{4}{|c|}{ Total Problems } \\
\hline & $\begin{array}{c}\text { Clinical } \\
(\%)\end{array}$ & $\begin{array}{c}\text { Non- } \\
\text { clinical } \\
(\%)\end{array}$ & PR (95\% Cl) & $\mathbf{p}$ & $\begin{array}{c}\text { Clinical } \\
(\%)\end{array}$ & $\begin{array}{l}\text { Non- } \\
\text { clinical } \\
(\%)\end{array}$ & PR (95\% Cl) & $\mathbf{P}$ & $\begin{array}{c}\text { Clinical } \\
\text { (\%) }\end{array}$ & $\begin{array}{l}\text { Non- } \\
\text { clinical } \\
(\%)\end{array}$ & PR (95\% Cl) & p \\
\hline \multicolumn{13}{|c|}{ Sociodemographic characteristics } \\
\hline \multicolumn{13}{|l|}{ Gender } \\
\hline Female & 27.59 & 72.41 & $1.35(0.66-2.76)$ & 0.41 & 22.41 & 77.59 & $1.1(0.52-2.33)$ & 0.81 & 25.86 & 74.14 & $0.95(0.5-1.82)$ & 0.87 \\
\hline Male & 20.45 & 79.55 & 1 & & 20.45 & 79.55 & 1 & & 27.27 & 72.73 & 1 & \\
\hline \multicolumn{13}{|l|}{ Age group (years) } \\
\hline 12 to 14 & 30.36 & 69.64 & $1.75(0.83-3.67)$ & 0.14 & 23.21 & 76.79 & $1.19(0.56-2.52)$ & 0.66 & 30.36 & 69.64 & $1.4(0.71-2.75)$ & 0.33 \\
\hline 15 to 17 & 17.39 & 82.61 & 1 & & 19.57 & 80.43 & 1 & & 21.74 & 78.26 & 1 & \\
\hline \multicolumn{13}{|l|}{ Ethnic group } \\
\hline White & 24.24 & 75.76 & $0.98(0.47-2.04)$ & 0.97 & 9.09 & 90.91 & $0.33(0.11-1.04)$ & 0.06 & 18.18 & 81.82 & $0.6(0.27-1.34)$ & 0.21 \\
\hline Non-White & 24.64 & 75.36 & 1 & & 27.54 & 72.46 & 1 & & 30.43 & 69.57 & 1 & \\
\hline \multicolumn{13}{|l|}{ Economic status } \\
\hline Class B2 & 23.08 & 76.92 & $1.62(0.38-6.84)$ & 0.51 & 30.77 & 69.23 & $1.29(0.42-3.95)$ & 0.65 & 30.77 & 69.23 & $1.29(0.42-3.95)$ & 0.65 \\
\hline Class C & 27.94 & 72.06 & $1.96(0.64-5.96)$ & 0.24 & 19.12 & 80.88 & $0.8(0.32-1.99)$ & 0.64 & 26.47 & 73.53 & $1.11(0.47-2.63)$ & 0.81 \\
\hline Class D & 14.29 & 85.71 & 1 & & 23.81 & 76.19 & 1 & & 23.81 & 76.19 & 1 & \\
\hline \multicolumn{13}{|l|}{ Religious background } \\
\hline No & 13.79 & 86.21 & 1 & & 24.14 & 75.86 & 1 & & 20.69 & 79.31 & 1 & \\
\hline Yes & 28.77 & 71.23 & $2.09(0.78-5.55)$ & 0.14 & 20.55 & 79.45 & $0.85(0.39-1.87)$ & 0.69 & 28.77 & 71.23 & 1.39 (0.63-3.09) & 0.42 \\
\hline \multicolumn{13}{|l|}{ Parents' marital status } \\
\hline Married or living together & 26.92 & 73.08 & $1.22(0.62-2.43)$ & 0.56 & 17.31 & 82.69 & $0.67(0.31-1.42)$ & 0.29 & 23.08 & 76.92 & $0.77(0.4-1.48)$ & 0.43 \\
\hline Single or divorced & 22 & 78 & 1 & & 26 & 74 & 1 & & 30 & 70 & 1 & \\
\hline \multicolumn{13}{|c|}{ Addicted family characteristics } \\
\hline \multicolumn{13}{|l|}{ Substance abuser member } \\
\hline Brothers & 25 & 75 & $0.85(0.14-5.02)$ & 0.86 & 0 & 100 & - & 0.99 & 0 & 100 & - & 0.99 \\
\hline Mother/father/both & 21.9 & 78.1 & $0.74(0.37-1.49)$ & 0.41 & 21.9 & 78.1 & $0.93(0.43-1.99)$ & 0.85 & 25 & 75 & $0.77(0.41-1.47)$ & 0.43 \\
\hline Other family member & 29.41 & 70.59 & 1 & & 23.53 & 76.47 & 1 & & 32.35 & 67.65 & 1 & \\
\hline \multicolumn{13}{|l|}{ Substance consumed } \\
\hline Illicit drugs & 32.56 & 67.44 & $1.69(0.85-3.34)$ & 0.13 & 27.91 & 72.09 & $1.77(0.82-3.81)$ & 0.15 & 37.21 & 62.79 & $1.93(1-3.72)$ & 0.05 \\
\hline Alcohol & 19.3 & 80.7 & 1 & & 15.79 & 84.21 & 1 & & 19.3 & 80.7 & 1 & \\
\hline \multicolumn{13}{|c|}{ Substance use by the adolescent } \\
\hline Alcohol & 30.77 & 69.23 & $1.38(0.67-2.81)$ & 0.38 & 34.62 & 65.38 & $2.02(0.98-4.17)$ & 0.06 & 42.31 & 57.69 & $2.01(1.08-3.76)$ & 0.03 \\
\hline Tobacco & 40 & 60 & $1.69(0.54-5.23)$ & 0.36 & 60 & 40 & $3.06(1.35-6.97)$ & 0.01 & 60 & 40 & $2.43(1.09-5.37)$ & 0.03 \\
\hline Illicit drugs & 66.67 & 33.33 & $2.87(1.19-6.89)$ & 0.02 & 66.67 & 33.33 & $3.3(1.35-8.04)$ & $<0.01$ & 66.67 & 33.33 & $2.64(1.11-6.29)$ & 0.03 \\
\hline \multicolumn{13}{|l|}{ Family psychosocial stressors } \\
\hline Psychiatric hospitalization & 37.5 & 62.5 & $1.60(0.61-4.21)$ & 0.34 & 12.5 & 87.5 & $0.56(0.09-3.64)$ & 0.54 & 37.5 & 62.5 & $1.47(0.56-3.83)$ & 0.43 \\
\hline Family severe disease & 21.74 & 78.26 & $0.86(0.36-2.04)$ & 0.73 & 26.09 & 73.91 & $1.29(0.57-2.91)$ & 0.54 & 26.09 & 73.91 & $0.98(0.45-2.14)$ & 0.96 \\
\hline Suicide & 50 & 50 & $2.08(0.50-8.70)$ & 0.31 & 50 & 50 & $2.38(0.57-10.02)$ & 0.24 & 100 & 0 & - & - \\
\hline Suicide attempt & 75 & 25 & $3.34(1.70-6.56)$ & $<0.01$ & 25 & 75 & $1.17(0.2-6.64)$ & 0.86 & 100 & 0 & - & - \\
\hline Problems with the law & 50 & 50 & $2.24(1.02-4.93)$ & 0.04 & 12.5 & 87.5 & $0.56(0.09-3.64)$ & 0.54 & 50 & 50 & $2.04(0.94-4.45)$ & 0.07 \\
\hline Death of a family member & 22.22 & 77.78 & $0.89(0.35-2.28)$ & 0.81 & 33.33 & 66.67 & $1.75(0.8-3.85)$ & 0.16 & 33.33 & 66.67 & $1.33(0.63-2.83)$ & 0.45 \\
\hline Aggression between family & 25 & 75 & $1.03(0.48-2.19)$ & 0.94 & 25 & 75 & $1.23(0.56-2.7)$ & 0.6 & 35.71 & 64.29 & $1.55(0.81-2.97)$ & 0.18 \\
\hline
\end{tabular}

95\% Cl: 95\% confidence interval.

Results in bold indicate statistically significant associations. 
Table 3. Exposure to domestic violence and increased risk of emotional and behavioral problems among adolescents $(N=102)$

\begin{tabular}{|c|c|c|c|c|c|}
\hline & Disorders & $n$ & Mean (SD) & PR (95\% Cl) & $\mathbf{P}$ \\
\hline \multicolumn{6}{|c|}{ Internalizing Problems } \\
\hline \multirow[t]{5}{*}{ Clinical } & Cognitive & 25 & $3.08(1.55)$ & $1.39(1.14-1.71)$ & $<0.01$ \\
\hline & Emotional & 25 & $7.96(3.1)$ & $1.16(1.10-1.23)$ & $<0.01$ \\
\hline & Social & 25 & $2.4(1.12)$ & $1.04(0.79-1.35)$ & 0.79 \\
\hline & Behavioral & 25 & $5.28(2.09)$ & $1.16(1.04-1.30)$ & $<0.01$ \\
\hline & Physical & 25 & $0.68(0.75)$ & $1.90(1.25-2.88)$ & $<0.01$ \\
\hline \multirow[t]{5}{*}{ Non-clinical } & Cognitive & 77 & $1.99(1.45)$ & & \\
\hline & Emotional & 77 & $4.87(2.77)$ & & \\
\hline & Social & 77 & $2.32(1.25)$ & & \\
\hline & Behavioral & 77 & $3.92(2.36)$ & & \\
\hline & Physical & 77 & $0.32(0.52)$ & & \\
\hline \multicolumn{6}{|c|}{ Externalizing Problems } \\
\hline \multirow[t]{5}{*}{ Clinical } & Cognitive & 22 & $2.91(1.51)$ & $1.28(1.04-1.59)$ & 0.02 \\
\hline & Emotional & 22 & $8(3.48)$ & $1.15(1.05-1.25)$ & $<0.01$ \\
\hline & Social & 22 & $2.23(1.27)$ & $0.92(0.66-1.27)$ & 0.61 \\
\hline & Behavioral & 22 & $6.23(2.18)$ & - & - \\
\hline & Physical & 22 & $0.64(0.66)$ & $1.64(1.02-2.62)$ & 0.04 \\
\hline \multirow[t]{5}{*}{ Non-clinical } & Cognitive & 80 & $2.08(1.51)$ & & \\
\hline & Emotional & 80 & $4.98(2.72)$ & & \\
\hline & Social & 80 & $2.38(1.21)$ & & \\
\hline & Behavioral & 80 & $3.71(2.11)$ & & \\
\hline & Physical & 80 & $0.35(0.58)$ & & \\
\hline \multicolumn{6}{|c|}{ Total Problems } \\
\hline \multirow[t]{5}{*}{ Clinical } & Cognitive & 27 & $3.3(1.41)$ & 1.5 (1.24-1.81) & $<0.01$ \\
\hline & Emotional & 27 & 7.81 (3.64) & $1.11(1.02-1.21)$ & 0.01 \\
\hline & Social & 27 & 2.22 (1.22) & $0.91(0.69-1.22)$ & 0.54 \\
\hline & Behavioral & 27 & $5.85(2.09)$ & - & - \\
\hline & Physical & 27 & $0.74(0.71)$ & $2(1.41-2.83)$ & $<0.01$ \\
\hline \multirow[t]{5}{*}{ Non-clinical } & Cognitive & 75 & $1.88(1.41)$ & & \\
\hline & Emotional & 75 & $4.84(2.54)$ & & \\
\hline & Social & 75 & 2.39 (1.22) & & \\
\hline & Behavioral & 75 & 3.68 (2.19) & & \\
\hline & Physical & 75 & $0.29(0.51)$ & & \\
\hline
\end{tabular}

95\% Cl: 95\% confidence interval.

Results in bold indicate statistically significant associations.

\section{DISCUSSION}

This study was conducted with a sample of adolescents who is highly vulnerable due to several factors, including living with at least one relative with SUD, mainly the father ${ }^{33}$. The overwhelming majority was exposed to at least an important stressor event in the last 12 months (including physical aggression and death), $14.3 \%$ do not use any birth control, and $25.5 \%$ are already consuming alcohol. Almost a quarter was exposed to domestic violence, and the outcomes of domestic violence (cognitive, emotional, behavioral, and physical disorder) were positively associated with increased risks of internalizing and externalizing problems. Those factors are known for predicting substance use $\mathrm{e}^{34}$.

Overall, $24.5 \%$ had score on the clinical range for Internalizing Problems, 21.6\% for Externalizing Problems, and $26.5 \%$ for Total Problems. The rates of emotional and behavioral problems are higher than the 13.4\% (Cl 95\% 11.3-15.9) worldwide pooled prevalence of children and adolescents affected by any mental disorder reported by Polanczyk et al. in a recent meta-analysis ${ }^{35}$. Such data reinforce the need to promote public mental health policies, 
which include protective interventions for children from disadvantaged family backgrounds, such as those living in this vulnerable neighborhood of São Paulo, Brazil.

Miettunen et al.36 found that externalizing problems may precede adolescent substance use in both genders, and, among boys, substance use also precedes criminal behaviors. The same study reported that internalizing problems may be followed by substance use in girls and that externalizing problems at age 8 years are associated with later substance use $^{36}$. After adjustment for sociodemographic factors, the authors found that criminality and substance use, especially among boys, can be predicted by parental alcohol use and psychiatric disorders, and by early externalizing and internalizing problems ${ }^{36}$. Moreover, girls' cannabis use (odds ratio $=3.2,95 \%$ $\mathrm{Cl}=1.4-7.3$ ) and alcohol use (odds ratio $=2.1,95 \% \mathrm{Cl}=1.1-4.2$ ) predicted internalizing disorders in adulthood ${ }^{36}$.

Meque et al.34, in a review of 12 longitudinal studies, observed that internalizing symptoms increased the risk of young adult alcohol use disorders by $21 \%$ (odds ratio $=1.21$; $95 \% \mathrm{Cl}=1.05-1.39$ ), and that externalizing symptoms increased the risk by $62 \%$ (odds ratio $=1.62,95 \% \mathrm{Cl}=1.39-1.90$ ).

Our findings are similar to those reported by other researchers ${ }^{34,36}$, and confirm data found in other countries ${ }^{10}$, including those with socioeconomic and cultural levels higher than Brazil ${ }^{7,8,13}$. Indeed, it is notetaking that gender, age group, ethnic group, economic status, religious background, and parental marital status had no association with an increased prevalence of internalizing, externalizing and total problems in our sample. Moreover, mother's and father's schooling did not predict increased emotional and behavioral problems, as was expected initially. Similar to what was found in a sample of 511 urban families in six LMICs (China, Colombia, Jordan, Kenya, the Philippines, and Thailand), consistent associations were found between chaos, danger, affectionate, and harsh parenting and adolescent adjustment problems. In that study, conducted by Deater-Deckard et al. ${ }^{10}$, there was some support for the hypothesis, with nearly all countries showing a modest indirect effect of maternal hostility (but not affection) for adolescent externalizing, internalizing, and scholastic problems. Results provide further evidence that chaotic homes and dangerous neighborhood environments increase the risk for adolescent maladjustment in LMICs contexts via harsher maternal parenting ${ }^{10}$.

Emotional and behavioral problems are associated with substance use, sometimes as predictors of the risk for use, sometimes because of substance use. After all, witch comes first, mental health problems or substance use problems? Rothman and Greenland ${ }^{37}$ showed an extensive analysis about the influence of genetic and environmental risk factors for common psychiatric and SUD in men and women. According to their study, to understand the causal mechanisms, important principles may be considered, such as (1) multicausality - A given disease can be caused by more than one causal mechanism, and every causal mechanism involves the joint action of a multitude of component causes; (2) interaction among causes - The causal pie model posits that several causal components act in concert to produce an effect. "Acting in concert" does not necessarily imply that factors must act at the same time. (3) strength of a cause A given specific causal mechanism, any of the component causes can have strong or weak effects.

In short, every case of diseases has both genetic and environmental causes ${ }^{37,38}$. Future investigations can explain how these factors are combined to produce the clinical outcomes observed in children of families affected by SUD. Because of the immense diversity of issues surrounding SUD, treatment requires multiple approaches that encompass different therapeutic settings. Thus, the most varied treatment modalities must be available in a process of continuum care according to the needs of each individual at that moment, respecting a path of care the evolves with the severity of the problem. Resources, ranging from primary prevention to complex interventions in inpatient units, should be integrated for an effective care policy. In Brazil, only $19.8 \%$ of the children/adolescents with a psychiatric disorder have used mental health treatment services in the last 12 months $^{39}$. Looking at this neglected demand does not mean "medicalizing childhood", but preventing future harm, especially that related to substance use. Furthermore, many studies have proved that prevention programs are highly advantageous, generating savings of up to 10 dollars for each dollar invested in treatments for alcohol and other substance abuse ${ }^{40}$.

Current prevention programs tend to act in a multifactorial and multidimensional way. In other words, it is desirable for preventive attention directed to several domains of the individual's life. Prevention programs should be designed to reinforce positive aspects (protective factors) in the life of the individual or of the group he is in and to reduce negative aspects (risk factors) that may be harmful to them. An organized society may charge response for governmental and non-governmental actions aimed at providing public services and policies that can minimize the risks of substance use. Preventive strategies are also those that focus on improving the quality of life of the community, strengthening family and institutional ties, and caring of the population physical and emotional health ${ }^{41}$.

Among the limitations of this study, the small convenience sample must be listed. Our data cannot be generalized because the study was conducted with a selected sample of adolescents who attend social programs, meaning they were able to access services that are not available for most adolescents. Population or representative studies of all similar services in the city of São Paulo might provide a broader 
picture of the problem. The procedure used to identify the relative with SUD is also a limitation. The information was given by the adolescent, and it reflects their perception of the relative's substance use. Although the researchers did not have access to the substance user, Family CAGE-AID is an advantageous instrument for its potential in detecting substance dependence in a community or epidemiological studies where the primary user may be unavailable or non-cooperative ${ }^{22}$.

Importantly, data were collected in a region that is difficult to access due to its location, the traffic dealers' domain, and the risk associated with this scenario. Thus, the rates found represent adolescents who had access to services and can be understood as "the tip of the iceberg", as indicators of how high these rates may be. Furthermore, it was also important to consider that the most severely compromised cases were either not located or refused to participate in the study. Although our data cannot be generalized, they can help us understand how harmful it can be to be exposed to substance use in the family, to domestic violence, and to live in a region of such socioeconomic vulnerability.

This study is also limited by non-measured data. The YSR gives the adolescents' perspective, but there was no access to the information given by parents about the adolescents' behavior problems. It would be very interesting to have information from a multiple-informant perspective. Finally, because of the cross-sectional design, we cannot establish a causal relationship between the studied variables and the increase in the prevalence of adolescents' mental health problems, but it does shed light on a positive relation, and on directions for further studies with this population.

The high prevalence of youth in this sample and in Brazilian general population living with at least one relative with SUD $^{9}$ highlights the potential breadth of substance use prevention and treatment needs for the whole family considering substance use treatment for the affected adults, and prevention and supportive services for their children ${ }^{6}$.

The findings of this study summarize efforts to give voice to a population that is extremely vulnerable to multiple risk factors during their development, including substance use in the family, poverty, and all associated psychosocial stress factors, as found in this study and in another study recently published with a sample of Brazilian children aged 6-11 years ${ }^{42}$.

\section{CONCLUSIONS}

Our findings indicate association between exposure to domestic violence and increased risk of internalizing and externalizing problems and substance use among adolescents' exposed to alcohol and illicit drugs in the family environment. These findings reinforce the need to develop public mental health policies, which include protective interventions to adolescents from disadvantaged family backgrounds.

\section{INDIVIDUAL CONTRIBUTIONS}

Thaís dos Reis Vilela - Contributed to the study conception and design, data analysis and interpretation, writing and review of the article and approval of the final version to be published.

Marina Monzani da Rocha - Contributed to the study conception and design, data analysis and interpretation, writing and review of the article and approval of the final version to be published.

Neliana Buzi Figlie - Contributed to the study conception and design, data analysis and interpretation, writing and review of the article and approval of the final version to be published.

Sandra Cristina Pillon - Contributed to the analysis and interpretation of data, writing and review of the article and approval of the final version to be published.

Alessandra Diehl - Contributed to the interpretation of the data, writing and review of the article and approval of the final version to be published.

Jair de Jesus Mari - Contributed to the study conception and design, data analysis and interpretation, writing and review of the article and approval of the final version to be published.

\section{CONFLICT OF INTERESTS}

The author(s) declared no potential conflict of interests with respect to the research, authorship and/or publication of this article.

\section{ACKNOWLEDGEMENTS}

This project is part of the Research and Innovation Grant for Prevention of Mental Disorders and Use of Alcohol and other Drugs, "Pesquisas e Inovações em Prevenção de Transtornos Mentais e Uso de Álcool e Outras Drogas", funded by the Brazilian Ministry of Health (TED: 176/2017).

The main author is supported by a doctorate scholarship from the Coordenação de Aperfeiçoamento de Pessoal de Nivel Superior (Capes) in Brazil (Finance Code 001).

\section{REFERENCES}

1. Rehm J, Shield KD. Global burden of disease and the impact of mental and addictive disorders. Curr Psychiatry Rep. 2019;21:10. 
2. Vederhus JK, Kristensen $\emptyset$, Timko C. How do psychological characteristics of family members affected by substance use influence quality of life? Qual Life Res. 2019; 28:2161-70.

3. Smith JM, Estefan A. Families parenting adolescents with substance abuse - recovering the mother's voice: a narrative literature review. J Fam Nurs. 2014;20(4):415-41.

4. Orford J, Velleman R, Natera G, Templeton L, Copello A. Addiction in the family is a major but neglected contributor to the global burden of adult ill-health. Soc Sci Med. 2013;78:70-7.

5. Rutherford HJ, Mayes LC. Parenting and addiction: neurobiological insights. Curr Opin Psychol. 2017;15:55-60.

6. Lipari RN, Van Horn SL. Children Living with Parents Who Have a Substance Use Disorder. The CBHSQ Report. Rockville, MD: Substance Abuse and Mental Health Services Administration; 2013-2017.

7. Raninen J, Elgan TH, Sundin E, Ramstedt M. Prevalence of children whose parents have a substance use disorder: findings from a Swedish general population survey. Scand J Public Health. 2016;44(1):14-7.

8. Manning V, Best DW, Faulkner N, Titherington E. New estimates of the number of children living with substance misusing parents: results from UK national household surveys. BMC Public Health. 2009:9:377.

9. Instituto Nacional de Políticas Públicas do Álcool e Drogas (INPAD). LENAD Família Levantamento Nacional de Famílias dos Dependentes Químicos. 2013. Available from: https://inpad.org.br/_lenad-familia/. Accessed on: Mar 20, 2020.

10. Deater-Deckard K, Godwin J, Lansford JE, Tirado LMU, Yotanyamaneewong S, Alampay LP, et al. Chaos, danger, and maternal parenting in families: links with adolescent adjustment in low- and middle-income countries. Dev Sci. 2019;22(5):e12855.

11. Haugland SH, Coombes L, Stea TH. Associations between parenting and substance use, meal pattern and food choices: a cross-sectional survey of 13,269 Norwegian adolescents. Prevent Med Rep. 2019;14:100862.

12. Hayakawa M, Giovanelli A, Englund MM, Reynolds AJ. Not just academics: paths of longitudinal effects from parent involvement to substance abuse in emerging adulthood. J Adolesc Health. 2016;58(4):433-9.

13. Pisinger VS, Bloomfield K, Tolstrup JS. Perceived parental alcohol problems, internalizing problems and impaired parent-child relationships among 71988 young people in Denmark. Addiction. 2016;111(11):1966-74.

14. Fidalgo TM, Sanchez ZM, Caetano SC, Andreoni S, Sanudo A, Chen Q, et al. Exposure to violence: associations with psychiatric disorders in Brazilian youth. Braz J Psychiatry. 2018:40(3):277-83.

15. Sistema Estadual de Análise de Dados (SEADE). Índice de Vulnerabilidade Juvenil (1) e População de 15 a 19 Anos, segundo Distritos do Município de São Paulo; 2000. Available from: http://produtos.seade.gov.br/produtos/msp/cvi/cvi1_001.htm. Accessed on: Mar 20,2020 .

16. LabHab - Laboratório de Habitação e Assentamentos Humanos da FAUUSP. Plano de Ação Habitacional e Urbano: Diagnóstico Jardim Ângela [Internet]. São Paulo: Laboratório de Habitação e Assentamentos Humanos/FAUUSP; 2003. Available from: http://www. fau.usp.br/depprojeto/labhab/biblioteca/produtos/plano_acaohaburb_diagnostico_ jdangela.pdf. Accessed on: Mar 20, 2020

17. Akerman M, Bousquat A. Mapas de risco de violência. São Paulo Perspec. 1999;13(4):112-20.

18. ABEP - Associação Brasileira de Empresas de Pesquisa. Critério de Classificação Econômica Brasil [Internet]. São Paulo: Associação Brasileira de Empresas de Pesquisa; 2008. Available from: http://www.abep.org/Servicos/Download.aspx?id=07. Accessed on: Dec 10, 2010.

19. Frank SH, Graham AV, Zyzanski SJ, White S. Use of the Family CAGE in screening for alcohol problems in primary care. Arch Fam Med. 1992;1(2):209-16.

20. Brown RL, Rounds LA. Conjoint screening questionnaires for alcohol and other drug abuse: criterion validity in a primary care practice. Wis Med J. 1995;94(3):135-40.

21. Basu D, Ghosh A, Hazari N, Parakh P. Use of Family CAGE-AID questionnaire to screen the family members for diagnosis of substance dependence. Indian J Med Res. 2016;143(6):722-30.
22. Castells MA, Furlanetto LM. Validity of the CAGE questionnaire for screening alcoholdependent inpatients on hospital wards. Rev Bras Psiquiatr. 2005;27(1):54-7.

23. World Health Organization. International Statistical Classification of Diseases and Related Health Problems (ICD-10). Porto Alegre: Editora Artes Médicas Sul; 1997.

24. De Micheli D, Formigoni MLOS. Screening of drug use in a teenage Brazilian sample using the Drug Use Screening Inventory (DUSI). Addict Behav. 2000;25(5):683-91.

25. De Micheli D, Formigoni MLOS. Psychometric properties of the Brazilian version of the drug use screening inventory. Alcohol Clin Exp Res. 2002;26(10):1523-28.

26. Achenbach TM, Rescorla LA. Manual for the ASEBA School-Age Forms \& Profiles Burlington, VT: University of Vermont, Research Center for Children, Youth, \& Families; 2001.

27. Rocha MM. Evidências de Validade do "Inventário de Autoavaliação para Adolescentes" (YSR/2001) para a População Brasileira [dissertação]. São Paulo: Universidade de São Paulo; 2012.

28. Agosta CB, Barilari Z, Colombo Rl. Abuso y Maltrato Infantil: Inventario de Frases. Buenos Aires: Sainte Claire; 2001

29. Agosta CB, Balarini Z, Colombo RI. Abuso y Maltrato Infantil Inventario de Frases Revisado (IFR). Buenos Aires: Cauquen Exdtora; 2005

30. Tardivo LSLPC, Pinto Junior AA. Inventário de Frases no Diagnóstico de Violência Doméstica Contra Crianças e Adolescentes (IFVD). São Paulo: Vetor Editora; 2010.

31. Figlie NB, Milagres E, Crowe J. Família e Dependência Química: Uma Experiência com Crianças e Adolescentes no Jardim Ângela. São Paulo: Editora Roca; 2009

32. Skov T, Deddens J, Petersen MR, Endahl L. Prevalence proportion ratios: estimation and hypothesis testing. Int J Epidemiol. 1998;27(1):91-5.

33. Salgado CAI, Rovaris DL, Vitola ES, Grevet EH, Bau CHD. The impact of the overlap between externalizing and internalizing problems on substance use disorders. Eur Child Adolesc Psychiatry. 2020;29(2):249-50.

34. Meque I, Dachew BA, Maravilla JC, Salom C, Alati R. Externalizing and internalizing symptoms in childhood and adolescence and the risk of alcohol use disorders in young adulthood: a meta-analysis of longitudinal studies. Aust New Zealand J Psychiatr. 2019:29:4867419844308.

35. Polanczyk GV, Salum GA, Sugaya LS, Caye A, Rohde LA. Annual research review: a metaanalysis of the worldwide prevalence of mental disorders in children and adolescents. J Child Psychol Psychiatry. 2015 Mar56(3):345-65.

36. Miettunen J, Murray GK, Jones PB, Mäki P, Ebeling H, Taanila A, et al. Longitudinal associations between childhood and adulthood externalizing and internalizing psychopathology and adolescent substance use. Psychol Med. 2014;44(8):1727-38.

37. Rothman KJ, Greenland S. Causation and causal inference in epidemiology. Am J Public Health. 2005;95 Suppl 1:S144-50

38. Kendler KS, Prescott CA, Myers J, Neale MC. The structure of genetic and environmental risk factors for common psychiatric and substance use disorders in men and women. Arch Gen Psychiatry. 2003;60(9):929-37.

39. Paula CS, Bordin IA, Mari JJ, Velasque L, Rohde LA, Coutinho, ES. The mental health care gap among children and adolescents: data from an epidemiological survey from four Brazilian regions. PLos ONE. 2014;9(2):e88241.

40. Robertson EB, David SL, Rao SA. Preventing drug use among children and adolescents: a research based guide for parents, educators, and community leaders. Bethesda, MD: U.S. Department of Health and Human Services, National Institutes of Health, National Institute on Drug Abuse; 2003.

41. Diehl A, Figlie NB. Prevenção ao Uso de Álcool e Outras Drogas. 0 Que Cada um de Nós Pode Fazer? Porto Alegre: Editora Artmed; 2014.

42. Vilela TR, Rocha MM, Figlie NB, Mari JJ. Association between psychosocial stressors with emotional and behavioral problems among children of low-income addicted families living in Brazil. Child Abuse Negl. 2019;92:12-21. 